\title{
Towards a Sustainable Reverse Logistics Framework / Typologies Based on Radio Frequency Identification (RFID)
}

\author{
Muhammad Usama \\ School of Business and Economics, \\ University of Management and Technology, Lahore, Pakistan \\ Email: Muhammad-usama@hotmail.com \\ Asher Ramish \\ Department of Operations and Supply Chain, \\ School of Business and Economics, \\ University of Management and Technology, Lahore, Pakistan \\ Email: asher@umt.edu.pk; asherramish@yahoo.com (Corresponding Author)
}

\begin{abstract}
In the past, closed loop supply chains (CLSCs) were not considered as value creating chains due to complexities and uncertainties in the product returns until the introduction of radio frequency identification (RFID) in the domain of supply chain (SC), which has made the product visibility possible in the CLSCs and has overcome the issues of uncertainties in product returns. There is a lack of research to configure RFID in closed loop supply chains or reverse logistics (CLSCs/RL). The objective of this paper is to develop the typology and propose the framework for configuring RFID in the CLSC/RL by categorizing the products based on RFID tagging and correspondingly finding the place of tagging RFID to the products in the CLSC/RL on the basis of product category in order to attain sustainability in an efficient and effective manner. Two typologies (pre-tagging and post-tagging) regarding deployment of RFID in sustainable and CLSC/RL are developed along with categorization of products as singlepiece and multi-piece products followed by a proposed conceptual framework for RFID configuration in Reverse Logistics domain. Empirical study is required to validate the proposed conceptual framework. The outcomes include: improvement in product visibility, forecasting accuracy, customer satisfaction, profit and market share and reduction in inventory cost and pollution.
\end{abstract}

Keywords: sustainability, radio frequency identification (RFID), closed-loop supply chain (CLSC), reverse logistics $(R L)$, framework, typology, typologies

\section{INTRODUCTION}

For the last few decades, industrialization has increased abruptly to fulfill the increasing demands of better life styles of the rapidly growing human population. This has resulted into environmental problems like global warming, depletion of resources, toxic waste consumption. Thus, with the increase in the consciousness over environmental issues, there arises a need for sustainability in supply chain. So manufacturers are compelled with the responsibility of sustainable supply chain management. One of the major and developing practices of achieving sustainability in supply chain is closing the loop of supply chain incorporating both forward and reverse logistics in supply chain. The concept of a CLSC has been studied by many authors from various aspects (Jayaraman et al., 1999; Guide, 2009; Neto et al., 2010).

Barbier (1987) described sustainability in terms of economic, environmental and social factors. Sustainability has become one of the major challenges of the modern era. Take back legislation imposed by European Union has enforced the manufacturers to take back the used products / components from the end consumers (Luk, 2009); and to recycle, reuse or remanufacture them in order to minimize as far as possible the environmental hazards of landfill and incineration (Andrea and Maria, 2016). But unfortunately, most of the companies are usually reluctant to invest in RL processes due to the complexities of various types of product returns and uncertainty associated with it, which makes the $\mathrm{RL}$ an inefficient and non-value adding process (Abdulrahman, 2012; Ngai, 2012). Thus, CLSC was not considered as a value creating chain (Jindal, 2011; Gunasekaran, 2012) until the introduction of RFID in SC, which has made the product visibility possible in the supply chain and resolved the uncertainty issues besides other problems like quality, counterfeiting, theft by making tracking and tracing of the product(s) possible (Choi and Yang, 2015). So, availability of accurate and updated information is necessary for sustainability (Melville, 2010). Digital technologies like RFID has a positive impact on reverse supply chain (Rogetzer and Nowak, 2018). RFID has a positive impact on green supply chain management (GSCM) practices (Bellah and Zelbst, 2016). A significant positive impact of RL was found by Barky (2016) on customer satisfaction in account of price and quality of remanufactured products. Therefore, we may say RFID has a positive impact on RL / sustainability. This along with optimization and generic algorithm models can integrate the entire SC to an ideally optimized level (Neslihan, 2014). Thus providing the organizations deploying RFID in RL, a competitive edge over others in the global supply chains.

As manufacturing is an important point in SC because it is the point of production to meet the demand at the consumption end and the cheapest place to tag RFIDs at item 
level (Ville, 2015) so, this paper emphasizes the manufacturers fully and other actors of the SC partially to employ RFID in CLSC/RL efficiently and meet the objectives of sustainability and customer satisfaction.

Few researchers have proposed frameworks to incorporate RFID in RL activities like disassembly (Sandani, 2013), remanufacturing (Zhou, 2013), recycling (King, 2015). Lee and Chan (2009) developed a system architecture for RFID based RL but did not mention the points of tagging and tracking (start/end) of RFID in CLSC/RL. Although typologies have been developed to configure RFID in the forward SC (Ville Hinkka, Maiju Häkkinen, Jan Holmström, Kary Främling, 2015) yet there is a lack of research to configure RFID in CLSC/RL. So the objective of this study is to develop the typology and propose the framework for configuring RFID in the CLSC/RL by categorizing the products based on RFID tagging and correspondingly find the place of tagging RFID to the products in the CLSC/RL on the basis of product category. In view of the objectives, following research questions arise:

RQ.1: What are the challenges related to the implementation of RFID in CLSC/RL?

RQ.2: What are the products categorized to be tagged with RFID in CLSC/RL?

RQ.3: Where to tag RFID to the products in the CLSC/RL? RQ.4: What will be the proposed sustainable framework to implement RFID in CLSC/RL?

Based on the above research questions, challenges related to the implementation (tagging and tracking) of RFID in CLSC/RL are picked from the literature. Products are categorized into two types (single piece and multi-piece) and correspondingly two typologies (pre-tagging and posttagging) to configure RFID are developed along with the framework to deploy RFID in CLSC/RL. Through this RFID technology in CLSC/RL, the major obstacles like return product(s) uncertainty, inventory inefficiency, stock-outs, forecasting inaccuracy which has rendered CLSC/RL as nonvalue adding chains, can be overcome effectively (GonzálezTorre et al., 2010).

The positive impact of RFID on sustainability and supply chain (SC) performance has been established by many researchers (Melville, 2010; Zelbst and Baker, 2010; Zelbst, Sower and Abshire, 2011; Bellah and Zelbst, 2016; Rogetzer and Nowak, 2018) but like forward SC (Ville Hinkka, Maiju Häkkinen, Jan Holmström, Kary Främling, 2015) there is a research gap in configuring RFID in CLSC/RL. So in this paper, two typologies have been proposed to deploy RFID in CLSC/RL taking typology developed for forward SC (Ville, 2015) as reference and extended it to be applicable for CLSC/RL using deductions made from extensive literature review and observations. A framework has been developed highlighting the obstacles to adopt RFID utilization while illustrating the drivers and objectives required to overcome these obstacles and emphasizing the outcomes of RFID adoption into CLSC/RL.

Hence, section 1 introduces the importance of RFID in CLSC/RL and its impact on sustainability. Section 2 contains the literature review, comprising various CLSC/RL frameworks involving few researches related to RFID in RL. Section 3 discusses the research questions and involves the proposed typologies/framework developed on the basis of research questions and finally section 4 concludes the paper involving limitations of the paper.

\section{LITERATURE REVIEW}

Logistics is a set of dynamic activities which acts as a bridge between supply and demand (Bartolacci, et al., 2012). By providing utility of place and time, logistics plays a vital role in the firm's competitiveness. Thus, innovation in logistics is a challenging area in supply chains which is developing day by day. Different logistics strategies like VMI, 3PLs, 4PLs and Reverse Logistics (RL) etc. have been introduced and are being implemented but the key for their success is technological development. RL provides a competitive edge to the organizations implementing it because according to resource-advantage theory, firms that pursue to utilize their resources in order to obtain competitive advantage ultimately results into increase in economic performance (Hunt and Morgan, 1996). Resourceadvantage theory states that competitive advantage (disadvantage) in the marketplace is due to comparative advantage (disadvantage) in resources (Hunt and Morgan, 1996). Resources involve the firm's assets, information, processes and knowledge that aid the firm to enhance its efficiency and effectiveness (Barney, 1991). According to the resource-advantage theory, the ultimate objective for firms is superior economic performance, which can only be accomplished by attaining a competitive advantage in the marketplace. Hunt and Morgan (1996) proposed that innovation plays a key role in resource-advantage theory. Firms will innovate to improve their resource position. Firms inhabiting positions of competitive advantage can maintain such positions by involving in proactive innovation, ensuring that their resources are comparatively better than the resources of their competing firms. Firms occupying positions of competitive disadvantage can attempt to surpass advantaged firms by involving in reactive innovation (Hunt, 2002). Generally, large firms have the capability, capacity, flexibility and feasibility over SMEs to employ technological innovation to implement RL so, according to Schumpeterian innovation framework, which considers the impact of firm size and available resources on firm innovation (Schumpeter, 1942). According to Schumpeter's perspective, large firms have greater capacity to innovate due to greater market power and research and development spending. On deploying technological innovation in RL follows S-curve theory explains the origins and evolution of radical innovations (Chandy and Tellis, 2000). S-curves develop as technologies are introduced. Little consumer advantage is achieved in the beginning phase, advantages increase abruptly as the technology develops, and finally advantages increase at a slower rate as the technology enters maturity (Chandy and Tellis, 2000). Thus in view of the theories discussed above, this paper focuses on the configuration of RFID (technological innovation) in the CLSC/reverse logistics.

\subsection{Supply Chain Management}

Cooper et al. (1997) defined SCM as "an integrative philosophy to manage the total flow of a distribution channel from supplier to the ultimate user." Thus, SCM involves both inter and intra-organizational coordination and integration of flow of material, information and cash to achieve the ultimate goal of inventory minimization (efficiency) and stock-out reduction (high service level) along with reduction 
in lead time (responsiveness) and optimization of logistics and other processes through implementing various strategies and technologies to minimize or overcome the issues of uncertainty, monitoring and control. Usually supply chain involves the flow of material from upstream to downstream and cash flow from downstream to upstream. Such a supply chain is referred as forward supply chain. On the contrary, supply chains having flow of material from downstream to upstream and cash flow from upstream to downstream, are referred as reverse supply chains. Information flow in both forward and reverse supply chains occur in both ways (i.e. from upstream to downstream and vice versa). The logistics activities involved in forward supply chain are termed as forward logistics whereas in reverse supply chain are known as reverse logistics.

\subsection{Reverse logistics and Closed-Loop Supply Chain (CLSC)}

Reverse logistics (RL) is defined as "the process of planning, implementing, and controlling the efficient and cost effective flow of raw materials, in-process inventory, finished goods, and related information from the point of consumption to the point of origin for the purpose of recapturing value or proper disposal" (Rogers, 2001). The objective of RL is to achieve sustainability in SC by overcoming the issues of environmental pollution via minimizing the incineration and/or land fill of EOL (end-oflife) or waste products, thus reducing their environmental burden at its source (Toffel, 2003). The integration of reverse logistics with the forward logistics results into closing the loop of the entire supply chain thus, constituting a CLSC. Thus CLSC is defined as "the design, control, and operation of a system to maximize value creation over the entire life cycle of a product with dynamic recovery of value from different types and volumes of returns over time" (Kannan, 2015).

Recycling, reuse, remanufacturing, refurbishing, reconditioning, revaluating, repairing and upgrading are the various RL activities described by different authors in the literature but Serge (2011) described remanufacturing, recycling and reuse as the three main factors in RL to meet the challenges of sustainability and globalization. Frameworks of CLSC are proposed in the literature by the different authors incorporating various RL activities and point of collection of returned items. Samir (2006) proposed a basic flow diagram of RL activities including repair, refurbishing, remanufacturing, recycling and disposal. Returned item (from customer) at the collection center is tested and send to the distribution center after repairing or refurbishing whereas the disassembled product is either send back to the distribution center after proper service or to the manufacturer for remanufacturing or incorporated to the raw materials after recycling. Tonanont et al. (2008) describes the similar type of flow for returned products while incorporating point of collection and return evaluation (decision) stage. After this, product is sent to the respective recovery facilities and the waste gets disposed. Lee and Chan (2009) proposed a framework for CLSC and developed a system architecture for RFID based RL system and developed a LP model using stochastic optimization method (Genetic Algorithm) to maximize the total coverage of customers who return products to the collection centers. A framework of product disposition options in CLSC is proposed by Kuan and Zulkifli (2012), which describes the similar RL activities as described by Samir (2006), Tonanont (2008) and Lee and Chan (2009) with the addition of reconditioning activity and its point of performance (Assembly stage) in the SC. Noor, Mehdi, Jamilahtun and Roslan (2016) developed a RL diagram from beverage industry's perspective and incorporated why, what, how and who components in the RL process. Joseph and Chunguang (2013) developed a detailed framework for RL activities with the addition of renewable systems, obsolete systems to the RL process. Thoney and King (2015) conducted a research regarding carpet CLSC and presented a RL framework depicting the recycling, refurbishing and remanufacturing of post-consumer carpets (PCC). The above discussed frameworks mentioned the point of collection and RL activities involved in RL process, but they fail to answer how to track and where to tag RFID in CLSC/RL.

\subsubsection{System Elements of Reverse Logistics}

Giuntini and Andel (1995b), Rogers and TibbenLembke (1998), Schwartz (2000), Marcoux, Riopel and Langevin (2001), Stock (2004) categorized gatekeeping, collection, sorting and disposal as four main steps of RL system. Serge (2011) proposed a conceptual framework of RL system containing seven elements (Figure 1). The key factor for the successful implementation of these steps of RL system is the interaction among various actors of the CLSC (Stock et al., 2006) which can be achieved efficiently and effectively via an integrated information system shown in Figure 1 by ensuring the product and process visibility.

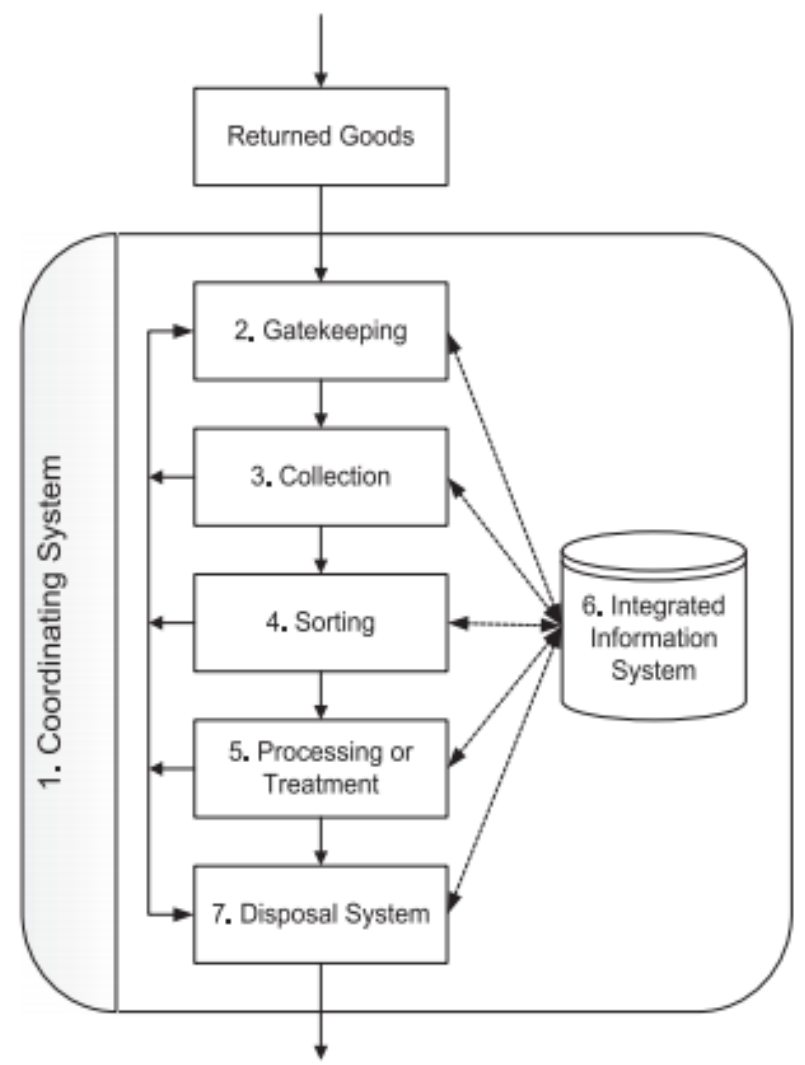

Figure 1 Conceptual framework of RL system elements proposed by Serge (2011) 


\subsubsection{Reverse Logistics practices}

The major RL practices include reuse, remanufacture and/or recycling (Serge, 2011) of the collected used, partly used and/or not used products. Thus, these form the constructs for RL practices (Nyarega, 2015) are described below:

- Reuse: Reuse is a mode of recovering partially used or completely unused product from the end consumer and put it back into the SC without any up gradation which results in the reduction of cost (Eltayeb et al., 2011). It also includes warranty failure products. Reuse practices involve returning partially or not used products to the supplier for reuse. Quality standard should be set for reuse purposes. Energy should be generated from renewable energy sources and product should be designed for reuse purposes (Rao \& Holt, 2005).

- Remanufacturing: Remanufacturing involves the product collection from the field which is then either go to manufacturer for repairing or overhauling. It includes replacement of product defective parts with the freshly prepared or brand new parts. Remanufacturing occurs when the returned back product did not meet the reuse standards (Toffel, 2004). Remanufacturing practices involve setting up repairing workshops and to train workers and employees for repairing or renovating or overhauling. There should be a warranty for remanufactured product for customer satisfaction, commonly practiced by electronics manufacturers like LG and Samsung who offer one year warranty on their remanufactured product also (Azevedo et al., 2011).

- Recycling: Recycling is a mode of recovering value from the used product returned from the customer in which useful material from the used products collected is extracted via disassembly while compromising the characteristics and functionality of the parent material (Eltayeb et al., 2011). Recycling is characterized by disassembling the used products collected and extracting the useful material from the EOL products. Recycling practices include returning used products to the supplier for recycling, creating public awareness by putting the recycling label on the products/packages. (Laosirihongthong et al., 2013) and by running pilot programs such as Nokia with the collaboration of Uniliver, in which the mobile user could renew his/her cell phone by recycling his old one.

For the success of CLSC, RL plays a critical role because RL can be adopted as a competitive strategy for the organization, a hub for asset recovery, a tool for the improvement of customer satisfaction. Thus assists the organizations in achieving the ultimate goal of increase in profit (Ritchie et al., 2000). RL also aids in overcoming the environmental and landfill problems, thus have a positive impact on human health which leads to the improvement in firm's citizenship (Li and Olorunniwo, 2008; Defee et al., 2009).

\subsection{RFID in Supply Chain}

\subsubsection{Roles of RFID in forward and reverse logistics}

In forward logistics, RFID plays a vital role in warehousing control and management, production scheduling and routing, tracing production conditions and quality issues, tracking material and product during transportation, theft prevention of expensive items, reducing stock-outs and improving customer service levels, reducing inventory costs, preventing short-life items and foods from spoilage. Thus increasing both the cost efficiency and responsiveness of the forward SC. In RL, RFID results in an increase in the customer's service levels regarding product recovery by providing product visibility and/or reducing lead time in recovery process. Moreover, RFID in RL improves the forecasting accuracy and inventory management by reducing the uncertainties of the returned goods.

A little work is done on deploying RFID in RL so this area is of great interest and needs attention to make the CLSCs to operate successfully and meet the challenges of globalization and sustainability. A framework for RFID tags progress in remanufacturing is proposed by Zhou (2013), shown in Figure 2. But it did not address the point of RFID tagging.

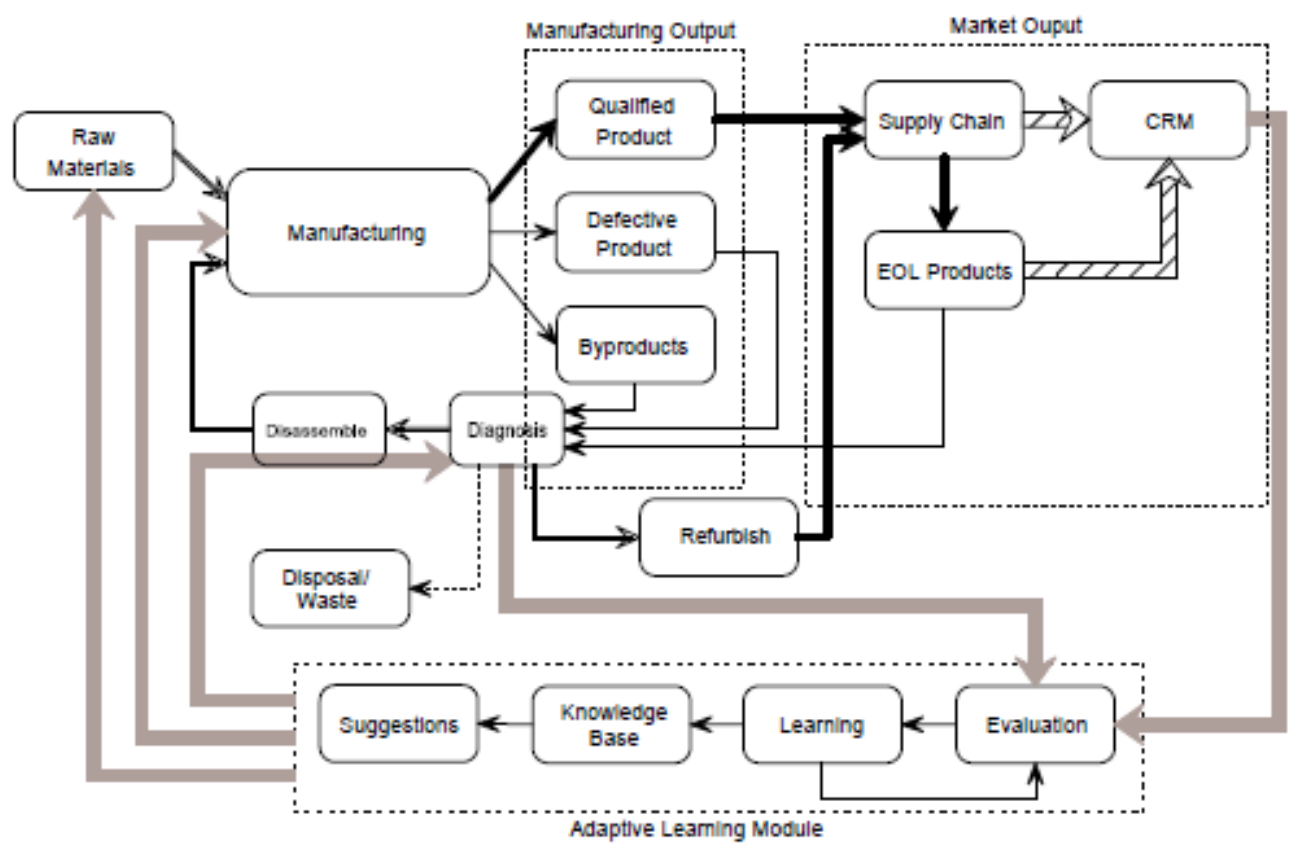

Figure 2 Framework for RFID tag progress through a supply chain by Zhou (2013) 
In the past, CLSCs were not considered as value creating chains (Jindal, 2011; Gunasekaran, 2012) due to complexities and uncertainties in the product returns and their drastic impact on the forward SC, so much of the focus was made on RL treatment processes rather than tracking of returned products via deploying RFID in RL system.

\subsubsection{Typologies of configuring RFID in Forward SC}

For the first time, Ville, Maiju, Jan and Kary (2015), developed the typologies for the configuration of RFID in a fashion supply chain (forward) using a case study approach involving LSP and its four fashion retailers. Three typologies developed for configuring RFID in forward supply chain (forward logistics) shown in Figure 3 are:

- Supply chain - wide tracking: In this type, tagging is done at the manufacturing site, which is the cheapest point of tagging in forward SC and tracking starts. Here item level tagging is also economical due to economies of scale. It covers the major part of the forward SC i.e. manufacturer to retailer so most of the actors of the forward SC can benefit from SC wide RFID tracking. Moreover, it is possible to trace back the manufacturing conditions and/or quality issues. It is expensive to track products at item level between manufacturing point and DC. For this, container level tracking will be most suitable. For expensive and/or sensitive products, SC wide tracking is a good option.
- Postponed tracking: In this typology, tagging is done at the manufacturing site, which is the cheapest echelon for tagging RFID in forward SC but tracking starts at the DC. This eliminates the cost of arrangements for tracking between manufacturing point and DC but due to incomplete tracking between manufacturing site and $\mathrm{DC}$, it is not possible to trace back the manufacturing conditions and/or quality issues back to the manufacturer. Actually, this type of tracking covers the most vital parts of the forward SC. i.e. DC to retailer.

- Postponed tagging: In this, both tagging is done and tracking is start at the DC echelon. Cost of item level tagging is higher relative to supply chain - wide tracking and postponed tracking. Almost all tags are exploited in the forward SC process.

It is noted from the typologies, shown in Figure 3, that supplier is not included in the supply chain, so on adding supplier to the above typology, and tagging the raw materials at the supplier echelon gives rise to a fourth typology, termed as "end-to-end supply chain tracking" (Figure 4 and 5). Here container or pallet level tracking will be more economically feasible. This broadens the visibility spectrum of the product. Thus, a product can be traced back to the supplier for quality issues and problems can be identified more easily by comparing the manufacturing process quality and raw material quality. End-to-End SC and supply chain - wide tracking are more feasible for vertically integrated firms.

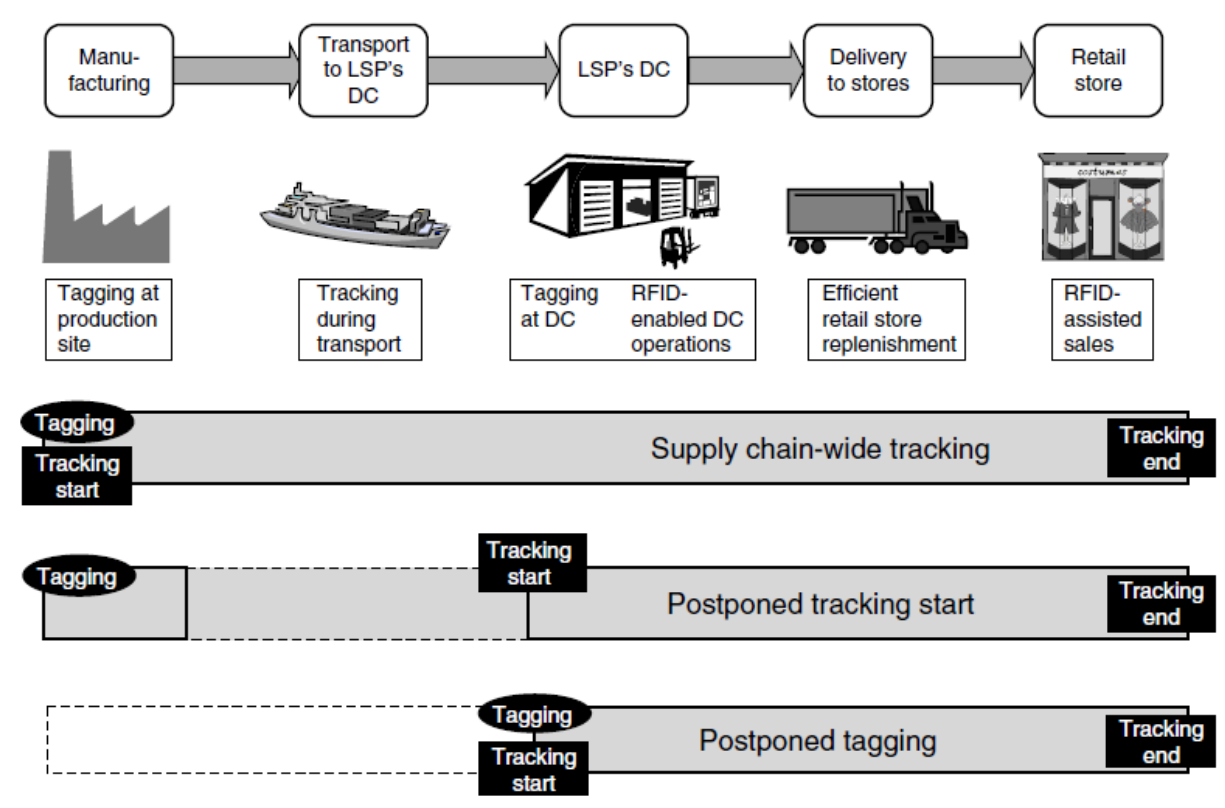

Figure 3 RFID configuration in forward supply chain by Ville, Maiju, Jan and Karry (2015)

\section{DISCUSSION}

In this portion, research questions are tend to be answered in view of literature review and deductions made through observations.

\subsection{Challenges to implement RFID in CLSC/RL}

From the literature review and gaps identified (González-Torre et al., 2010; Cosmin, 2010; Abraham, 2011) in the form of research questions, it is found that there are two stages of challenges encountered in configuring RFID in RL/CLSC.
The first stage is to adopt and implement RL processes and activities. The challenges encountered during this stage includes: hesitation of stakeholders to invest and top management commitment to implement RL due uncertainty in the product returns from the customer and product visibility in the RL process(s); lack of information sharing system (González-Torre et al., 2010); selecting the suitable process(s) for the product in order to maximize the value extracted from the return product because value of product depreciates with time (Cosmin, 2010); feasibility of the RL process, collaboration (Abraham, 2011) or outsourcing strategy used due to economic infeasibility and technical 
incapability of the company to implement RL process(s) and selecting the suitable technology (EDI, RFID etc.) for RL process(s). The second stage (gap found in literature) is to configure RFID in RL/CLSC. The challenges confronted during this stage are: selecting and categorizing the product(s) for RL, identifying the suitable place in the CLSC to configure RFID tags and selecting the type of tags (active, passive, rewritable, zombie etc.).

To overcome these obstacles, at first, top management commitment to adopt RL and change of mindset of the stakeholders to invest for technological up-gradation is necessary to formulate objectives by understanding the influence of drivers on the business growth and survival. After thorough study from the literature and typologies discussed in Figure 3, it is found that the typologies of configurable RFID tracking is given only for forward SC in fashion industries by Ville, Maiju, Jan and Karry (2015). There is a lack of research in developing typology or framework for configuring RFID in RL/CLSC. In this paper, a framework is proposed and typologies are developed for configuring RFID in CLSC/RL.

\subsection{Typologies of configuring RFID in CLSC}

Based on the literature review and drawing deductions from the RL/CLSC frameworks (Samir, 2006; Sandani, 2013; Zhou, 2013; King, 2015; Ville, 2015), RQ2 and RQ3 are answered as follows:

\subsubsection{Categorization of the products based on RFID tagging in CLSC/RL}

Based on the proposed typologies, products are to be categorized as single-piece products or multi- piece products.

- Single-piece products: These include those products which are not assembled/disassembled. These type of products mostly undergo recycling such as books/notebooks, newspapers, packaging material, printing papers, plastic items, iron/steel products, cells, batteries, iron/steel and plastic scrap etc.

- Multi-piece products: Products which are assembled/disassembled fall in this category. These type of products usually undergo remanufacturing, reconfiguration, refurbishing and/or repairing etc. such as cell phones, photocopier machines, cars, bikes, TVs, computers etc.

The end-of life (EOL) and/or waste products usually undergo recycling or get disposed, depending upon which is more suitable on the basis of technology to use, RL method to apply, economic feasibility, capacity and capability to employ the RL method and technology. For such complex situations, multi-objective linear programs (MOLP) are used for making decisions.

\subsubsection{Point of RFID tagging in the CLSC/RL}

On the basis of product classification as single-piece or multi-piece products, two typologies for RFID configuration in CLSC have been developed taking customer and/or end consumer as the datum:

- Pre-tagging: In pre-tagging (Figure 4), products are tagged before customer (end consumer) in the forward supply chain (end to end SC tracking, supply chain wide tracking, postponed tracking and postponed tagging). For multi-piece (usually expensive) items, which are made by assembling various sub-items; pretag RFID configuration is to be used. Such as electronic components (laptops, mobiles, printers etc.) automobiles (like cars, bikes etc.) and machineries (like cranes, $\mathrm{CNC}$, lathe machine, milling machine etc.). As pre-tagged items are usually expensive, so re-writable or zombie tags are usually used for these items. Tags are deactivated at the retailer site as the customer takes the product out of the retailer's vicinity after buying. Tag gets reactivated when the customer returns the product at the collection center.

- Post-tagging: In post-tagging (Figure 5), products are tagged after customer returns the product at the collection center (at the sorting stage) in the reverse supply chain (reverse logistics). For single-piece items, which are not made by assembling sub-items; post-tag RFID configuration is preferred to be used. Such as paper industry, glass manufacturers, iron and steel mills, packaging industry etc. As post-tagged items are usually inexpensive, so passive tags are usually employed at pallet or container level at sorting stage.

\subsection{Framework development for RFID configuration in RL/CLSC}

In view of the literature review and typologies developed in Figure 4 and Figure 5, a framework to implement RL and configure RFID in RL/CLSC is proposed as shown in Figure 6. As described earlier in challenges, (the first stage) obstacles to adopt RL shown in framework Figure 6, are top management commitment, selection of suitable RL process, collaboration and/or outsourcing RL activity (if economically not feasible internally), uncertainty in product returns (Gonzalez-Torre et al., 2010) and selection of technology (such as EDI, RFID etc.) to improve product visibility and reduce uncertainty. When top management and stakeholders are committed to formulate objectives (sustainability and customer satisfaction) while understanding the influence of drivers (competition, pressure from government in the form of take-back legislation, environmental issues etc.) on the growth and survival of business in global SC in the long run, then the obstacles to implement RL are surpassed by the objectives and drivers of implementing CLSC/RL.

Ideally every product produced should be returned back to the forward SC (usually manufacturer) to achieve sustainability but actually every item cannot undergo RL process(s) due to lack of technologies, technical incapability of the company or economic non-feasibility of the RL process. So company's objectives (sustainability and customer satisfaction) and drivers (competition, take back legislation, landfill issues and environmentally hazardous products) play a vital role in selecting items (i.e. electronic waste) for RL which are: (1) recommended/suggested by the government in the take back legislation to attain incentives from the government in the form of relaxation in taxes etc.; (2) less expensive; (3) can be easily remanufactured, recycled or reused; (4) environmentally hazardous if landfilled or incinerated conventionally etc.

After this the suitable process(s) (recycle, reuse, remanufacture) is selected for the respective RL product(s). Cost analysis of the selected process(s) involving cost of 
RFID tagging, is then performed and compared with the product profitability. If the RL process is economically feasible and the company is technically capable, perform it internally. Otherwise, outsource it or collaborate with other company (joint venture) or group of companies (consortium). Now product(s) is/are categorized as singlepiece or multi-piece product(s) $(R Q .1)$ and a respective RFID configuration typology is adopted (post-tagging or pretagging) (RQ. 2).

Finally, the outcomes for configuring RFID in RL/CLSC shown in framework (Figure 6) include: (1) Improvement in product visibility (Choi and Yang, 2015); (2) improvement in forecasting accuracy (Gonzalez-Torre et al., 2010); (3) reduction in inventory cost; (4) improvement in customer satisfaction (Barky, 2016). Hence, improvement in profit (Wang and Wong, 2013) and market share and reduction in pollution (Andrea and Maria, 2016), especially landfill related environmental problems.

Zhou (2013) and Thoney (2015) has incorporated RFID in RL activities like remanufacturing and recycling respectively but they did not point the place of tagging and tracking (start/end) of RFID in CLSC/RL. Neither have they categorized the products on the basis of tagging. So, this creates a research gap in the literature regarding configuration of RFID in CLSC/RL. Although research have been done regarding importance and impact of RFID in CLSC and RL yet like forward SC (Ville, 2015), there is a research gap in developing typology/framework for deploying RFID in CLSC/RL. This paper tries to fill these gaps based on deductions made through observations and literature review.
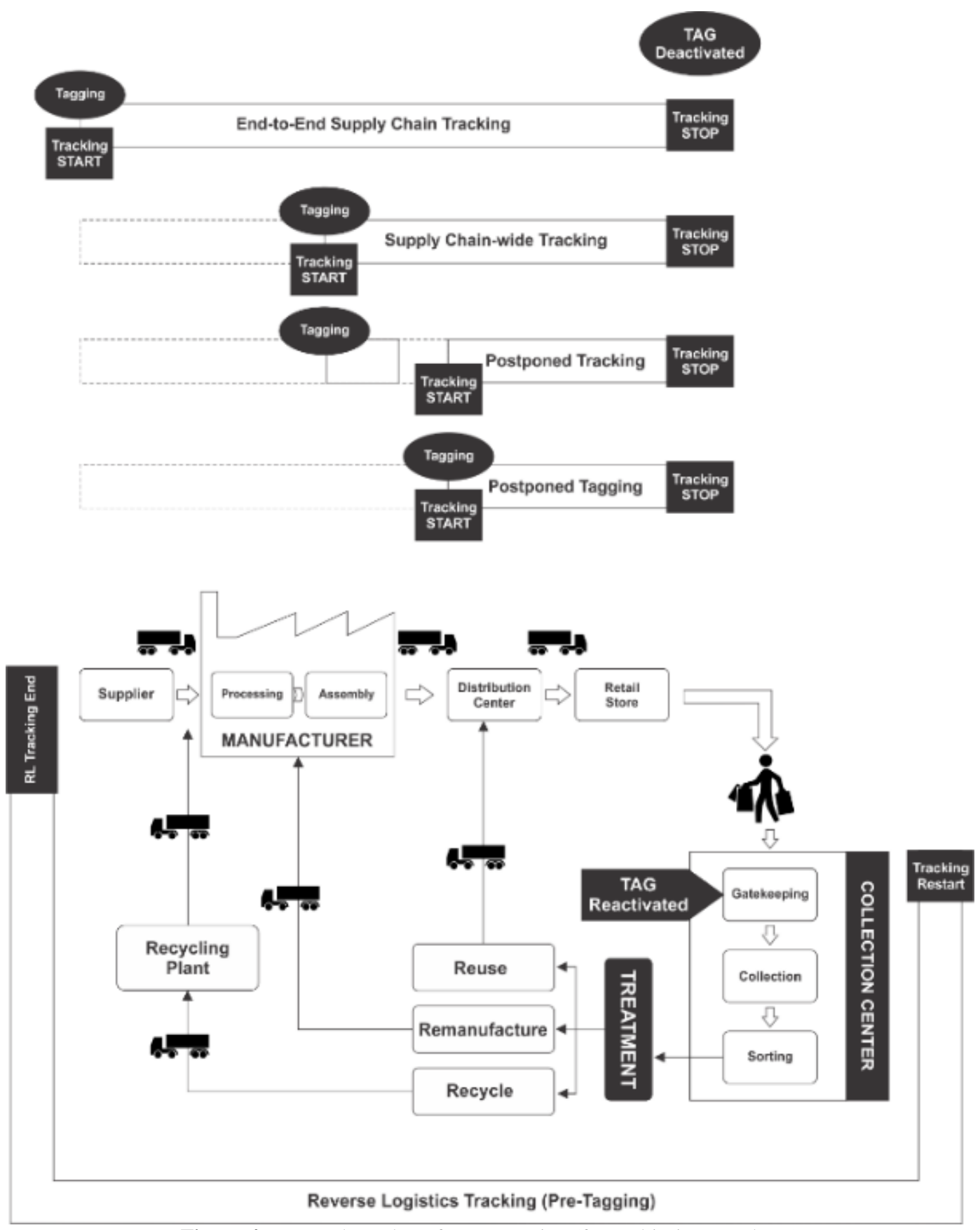

Figure 4 Proposed typology for pre-tagging (for multi-piece products) 


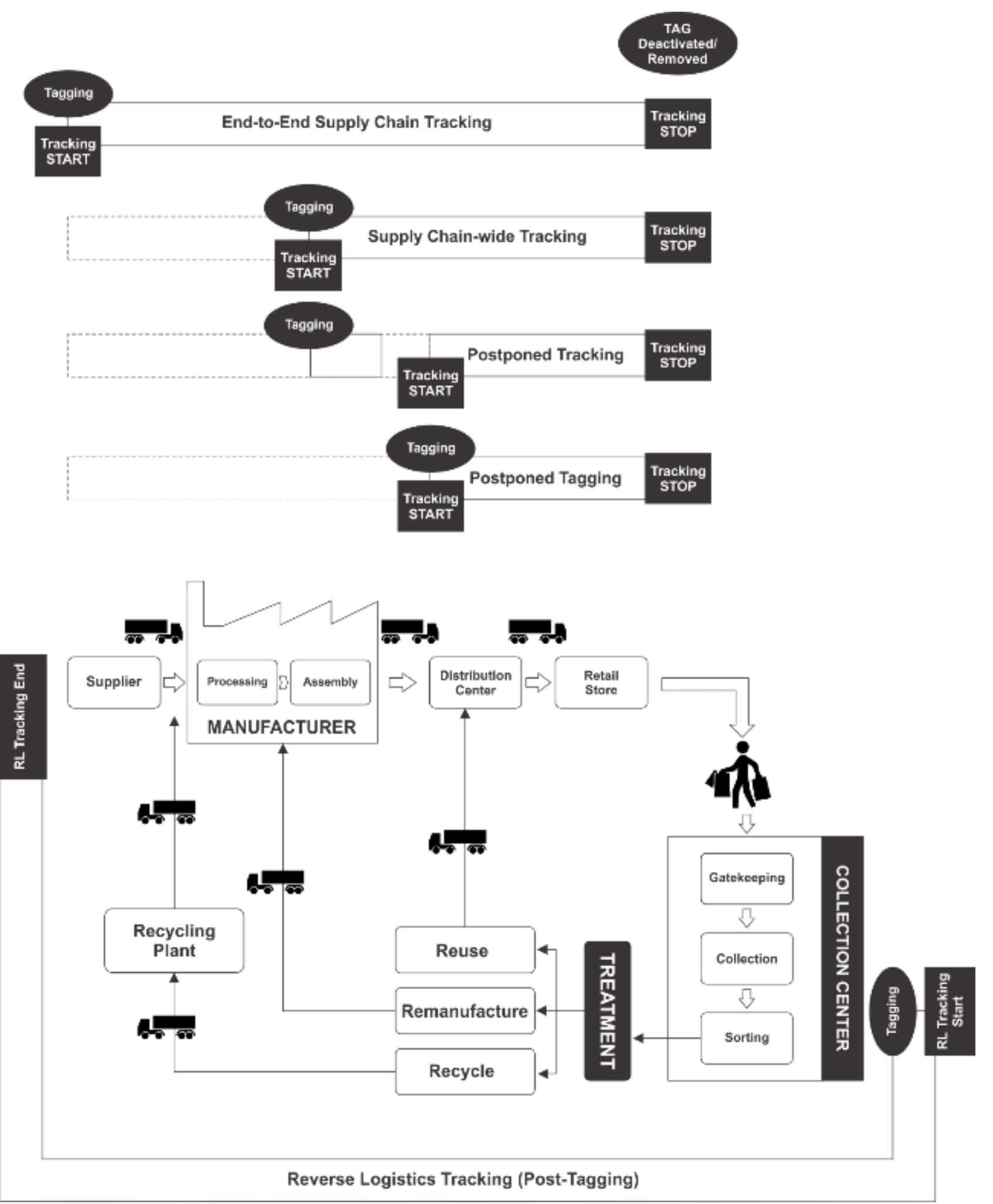

Figure 5 Proposed typology for post-tagging (for single-piece products) 


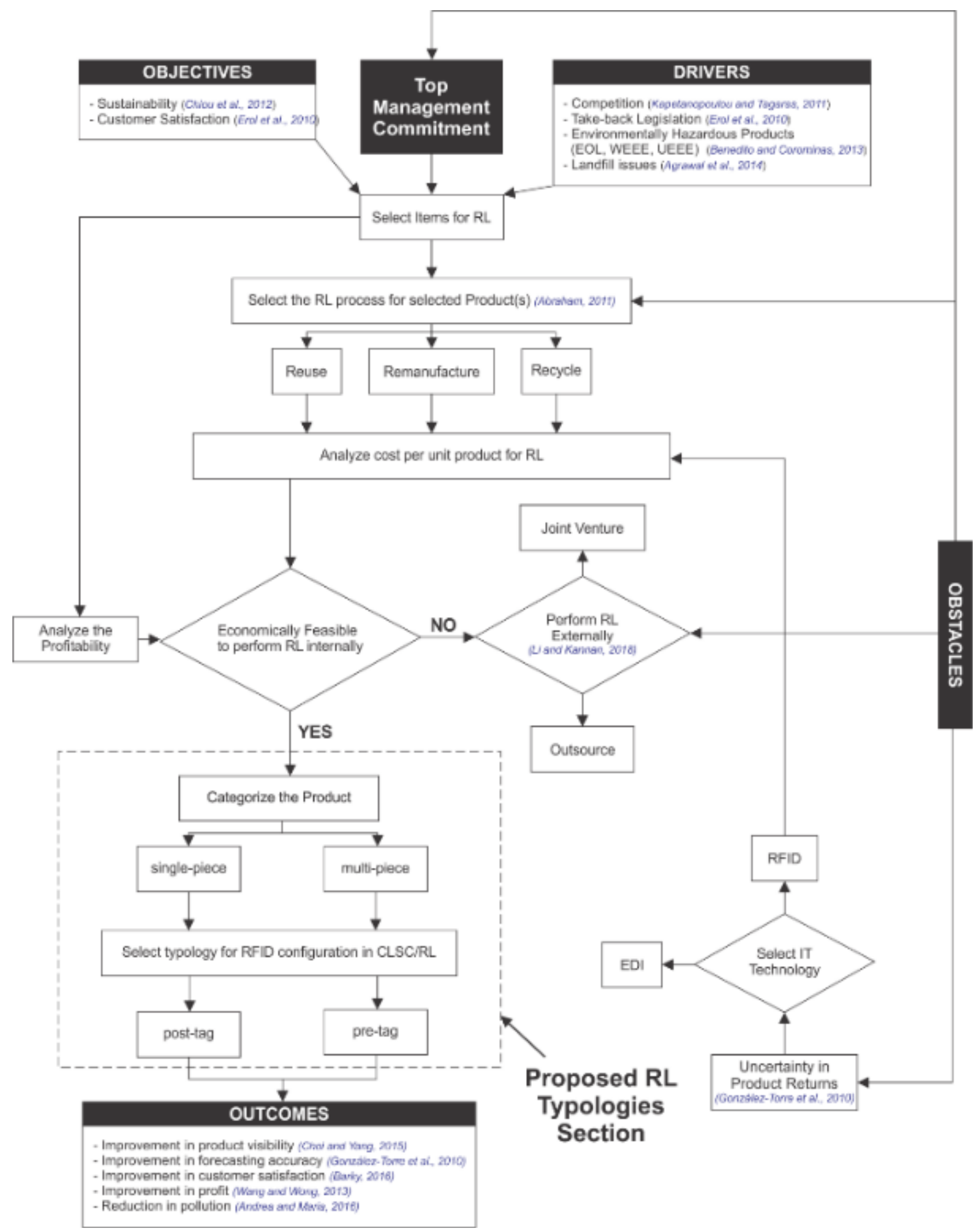

Figure 6 Proposed framework to implement RL and configure RFID in RL 


\section{CONCLUSION}

Much of the work has been done on RL and many RL frameworks have been proposed by different researchers (Samir, 2006; Tonanont et al., 2008; Lee and Chan, 2009; Kaun and Zulkifli, 2012; Joseph and Chunguang, 2013; Noor, Mehdi, Jamilahtun and Roslan, 2016). Few researchers tried to incorporate RFID in RL activities like remanufacturing (Zhou, 2013), recycling (Thoney and King, 2015). Ville (2015) developed the typologies for configuring RFID in Forward SC. But there is a lack of research in developing typology and framework for configuring RFID in RL/CLSC. So, after thorough research from the literature and following the typologies for configuring RFID in forward supply chain of fashion industry; two typologies (pre-tagging and post-tagging) regarding deployment of RFID in CLSC/RL are developed along with categorization of products as single-piece and multi-piece products. Moreover, "end-to-end supply chain tracking" typology is added as the fourth typology in the forward SC typologies (supply chain wide tracking, postponed tracking and postponed tagging developed by Ville Hinkka, Maiju Häkkinen, Jan Holmström, Kary Främling (2015)) and a framework is proposed for configuring RFID in Reverse Logistics.

The limitation of this research is that the typologies developed and framework proposed for configuring RFID in RL/CLSC are based on literature review and observations. These developed typologies and proposed framework for RFID in RL need to be verified for content and construct validity by using triangulation of data method via conducting interviews (from academicians, industrial experts (practitioners), consultants) and surveys. There will be a difficulty in selecting the sample frame for conducting interviews and surveys in developing countries like Pakistan due to lack of top management commitment and stakeholders' reluctances to invest in IT development. RL is implemented in many industries like iron and steel industry, packaging and paper industry, glass industry and plastic industry but configuration of RFID in their RL process(s) is still a question. For these reasons MNCs like Boeing, BMW, Dell Inc. HP etc. can be selected as a sample frame. Thus online survey typos will be used and skype interviews will be conducted in such case to verify the typologies developed and framework proposed for configuring RFID in RL.

Moreover, obstacles involving collaborative strategy (such as joint venture) and outsourcing strategy in conducting RL operations externally due to lack of internal feasibility, capability or capacity to conduct RL operations successfully, are out of the scope of this framework (Figure 6). Similarly in selecting a suitable IT system, only RFID technology is to be considered in the framework. Furthermore, it can be shown via survey results that configuring RFID in RL has a positive impact on organizational performance of the CLSC and customer satisfaction.

\section{REFERENCES}

Adebayo, S. (2014). Empirical Study of the Effect of Reverse Logistics Objectives on Economic Performance of Food and Beverages Companies in Nigeria. International Review of Management and Business Research, 3 (3), pp. 1484 - 1493.
Anthony Cline, S. L. (2015). A framework for reverse logistics: the case of post-consumer carpet in the US. International Journal of Commerce and Management, 25 (4), pp. 466 - 489.

Barbier, E. B. (1987). The Concept of Sustainable Economic Development. Environmental Conservation, 14 (2), pp. 101 110.

C.K.M. Lee, T. C. (2009). Development of RFID-based Reverse Logistics System . Expert Systems with Applications 36 (5), pp. $9299-9307$.

Cosmin Condea, F. T. (2010). Assessing the impact of RFID and sensor technologies on the returns management of timesensitive products. Business Process Management Journal, 16 (6), pp. 954-971.

Grawe, S. J. (2009). Logistics innovation: a literature-based conceptual framework. The International Journal of Logistics Management, 20 (3), pp. 360 - 377.

Hamed, K. a. (2015). Reverse logistics and closed-loop supply chain: A comprehensive review to explore the future. European Journal of Operational research, 240 (3), pp. 603 $-626$

Iurii Sas, K. A. (2015). Reverse Logistics of US Carpet Recycling. Sustainable Fashion Supply Chain Management, 1, pp. 3-30.

John K. Visich, S. L. (2007). Enhancing Product Recovery Value in Closed-Loop Supply Chains with RFID. Journal of Managerial Issues, 19 (3), pp. 436-452.

Kenneth W. Green Jr., P. J. (2016). Impact of Radio Frequency Identification Technology on Environmental Sustainability. Journal Of Computer Information Systems, 57 (3), pp. 1 - 9.

Kun Yang, D. F. An RFID-based Technology for Electronic Component and System Counterfeit Detection and Traceability. Paper presented at: IEEE 2015. Proceedings of International Symposium on Technologies for Homeland Security (HST); 2013 Apr 14-15; Waltham, MA, USA.

Lars Thoroe, A. M. RFID in Reverse Logistics Research Framework and Roadmap. Paper presented at: Business services: concepts, technologies, applications 2009. Proceedings of the 9th International Conference on Information Systems; 2009 Feb 25-27, Wein.

Muhammad D. Abdulrahman, A. G. (2014). Critical barriers in implementing reverse logistics in the Chinese manufacturing sectors. International Journal of Production Economics, 147, pp. $460-471$.

Mwaura Anne, L. N. (2016). Reverse Logistics Practices and Their Effect on Competitiveness of Food Manufacturing Firms in Kenya. International Journal of Economics, Finance and Management Sciences, 3, pp. 678-684.

Neslihan Demirel, H. G. (2014). A genetic algorithm approach for optimising a closed-loop supply chain network with crisp and fuzzy objectives. International Journal of Production Research, 52 (12), pp. 3637-3664.

Nigel P. Melville, S. M. (2010). Information Systems Innovation For Environmental Sustainability. MIS Quarterly, 34 (1), pp. $1-21$.

Noor Irdiana Binti Ngadiman, M. M. (2016). Reverse Logistics in Food Industries: A Case Study in Malaysia. International Journal of Supply Chain Management, 5 (3), pp. 91-95.

Pamela J. Z, K. W. (2011). Radio frequency identification technology utilization and organizational agility. Journal of Computer Information Systems, 52 (1) pp. 24-33.

Pamela J. Zelbst, K. W. (2010). RFID utilization and information sharing: the impact on supply chain performance. Journal of Business \& Industrial Marketing, 25 (8), pp.582-589.

Rogetzer, P. N. (2018). Impact of Digitalization on Sustainable Supply Chains: Ökonomische und soziologische Perspektiven. Chancen und Grenzen der Nachhaltigkeitstransformation, pp. 131 - 144.

S.H. Choi, B. Y. (2015). RFID tag data processing in manufacturing for track-and-trace anti-counterfeiting. Computers in Industry, 68, pp. 148-161. 
Sandani, E. System Dynamics simulation for investigating RFID potential in aircraft disassembly operations [master's thesis], Montreal, Quebec, Canada: Concordia University, 2013, $175 \mathrm{p}$.

Serge Lambert, D. R.-K. (2011). A reverse logistics decisions conceptual framework. Computer and Industrial Engineering, 61, pp. $561-581$.

Souza, M. E. Closed-Loop Supply Chains: New Developments to Improve the Sustainability of Business Practices. Boca Raton, Florida: Auerbach Publications Taylor \& Francis Group LLC, 2010.

Udin, K. S. (2012). Impact of Reverse Logistics Product Disposition towards Business Performance in Malaysian
E\&E Companies. Journal of Supply Chain and Customer Relationship Management, 2012, pp. 1 - 19.

Ville Hinkka, M. H. (2015). Supply chain typology for configuring cost-efficient tracking in fashion logistics. The International Journal of Logistics Management, 26 (1), pp. 42 - 60.

Wei Zhou, S. P. (2013). Remanufacturing with RFID item-level information: Optimization, waste reduction and quality improvement. International Journal of Production Economics, 145 (2), pp. 647 - 657.

Yongbo Li, D. K. (2018). Business orientation policy and process analysis evaluation for establishing third party providers of reverse logistics services. Journal of Cleaner Production, 182, pp. 1033 - 1047.

Muhammad Usama is a researcher and practitioner in the field of Operations and Supply Chain Management. He has completed his B.Sc. Mechanical Engineering from University of Engineering and Technology (UET), Lahore, Pakistan and has completed his MS in Supply Chain Management from the School of Business and Economics, University of Management and Technology (UMT), Lahore, Pakistan. He has a professional experience of 3 years in logistics and supply chain domain. His current research areas include Sustainable Supply Chain Management, RFID and System Dynamics.

Asher Ramish. With 17 years of diverse and global experience, Asher Ramish has developed his expertise in the domain of Supply Chain Management and Logistics. He has authored number of research papers in his ardent area too. Asher has been an AD-HOC member of reviewer board of 9 ISI impact factor journals. He is also editorial board member of two supply chain journals that are indexed in SCOPUS. Besides his enrollment in doctorate program in supply chain management, Asher previously, has done his MS in Production Management from Technical University of Hamburg-Harburg, Germany. He also holds a Bachelor in Mechanical Engineering from University of Engineering and Technology (UET), Lahore. 